\title{
Effect of Isoxsuprine on Fetal Lung Surfactant in Rabbits
}

\author{
VALLOP KANJANAPONE, M.D., ${ }^{(22)}$ IMME HARTIG-BEECKEN, AND MICHAEL F. EPSTEIN, M.D. \\ Department of Pediatrics, Harvard Medical School, Boston, Massachusetts, USA
}

\section{Summary}

To examine the effect of beta adrenergic drugs on fetal lung development, we administered isoxsuprine to pregnant rabbits for $24 \mathrm{hr}$ and measured indices of pulmonary surfactant synthesis, storage, and release in rabbit fetuses at $\mathbf{2 6}$ days gestation. Incorporation of radiolabeled choline into total and disaturated phosphatidylcholine was measured in vitro in fetal lung slices. There was a significant increase in the rate of choline incorporation into disaturated phosphatidylcholine in the isoxsuprine-treated group and a tendency toward an increased incorporation into total phosphatidylcholine as well. We also observed an increase in the pulmonary phospholipid reservoir as evidenced by a significant increase in total lung disaturated phosphatidylcholine and a trend toward higher total lung phosphatidylcholine in the isoxsuprine group. In addition, there was a significant increase in lung lavage $L / S$ ratio in the treated fetuses and in lung deflation stability determined by pressure volume curve. We conclude that isoxsuprine increases synthesis, storage, and release of surfactant in rabbit fetuses at $\mathbf{2 6}$ days gestation.

\section{Speculation}

The effect of isoxsuprine to increase lung disaturated phosphatidylcholine synthesis which leads to an increase in total lung disaturated phosphatidylcholine is probably mediated through an increase in intracellular cyclic adenosine monophosphate. It is possible that cyclic adenosine monophosphate can activate inactive forms of the enzymes of the choline incorporation and/or remodelling pathways within the fetal lung cells and enhance disaturated phosphatidylcholine synthesis.

Beta adrenergic agonists such as isoxsuprine have been used in obstetric practice as labor suppressants to inhibit premature uterine contractions (18). Several clinical reports have described either decreased or unchanged risk of respiratory distress syndrome (RDS) after fetal exposure to beta-adrenergic drugs in mothers with premature labor $(2,3,10,17)$.

Postnatal survival of premature infants depends on the presence of an adequate amount of pulmonary surfactant on the alveolar surface to prevent the collapse of alveoli. The major component of pulmonary surfactant by weight is phosphatidylcholine (PC), mainly in the form of disaturated phosphatidylcholine (DSPC) (6). Alveolar concentration of surfactant depends on its synthesis, storage, release, and degradation.

Previous studies of the fetal lung both in vivo $(1,3,4,12,21)$ and in vitro (16) have observed that beta adrenergic drugs cause an increase in surfactant release. This raises the question of whether the use of these drugs in premature labor could lead to a depletion of fetal lung surfactant stores and increase the risk of RDS. The only previous study that has examined the effect of these drugs on surfactant synthesis and storage, as well as release, produced conflicting conclusions because lung PC concentration increased despite a decrease in their measure of PC synthesis (9). To examine the net effect of a beta adrenergic drug on fetal lung phospholipid metabolism, we determined the rate of choline incorporation into PC and DSPC in fetal lung slices, lung tissue concentration of $P C$ and DSPC, and the $L / S$ ratio in lung lavage fluid and lung pressure-volume relationships in rabbit fetuses at 26 days gestation with and without exposure to isoxsuprine.

\section{MATERIALS AND METHODS}

The experiments were carried out in 21 New Zealand White rabbits with known times of mating. The control groups were given injections of three doses of saline every eight $\mathrm{hr}$ and delivered $24 \mathrm{hr}$ after the first dose at 26,28 , or 30 days gestation, respectively. There was a total number of 7 litters at 26 days and 4 litters, each at 28 and 30 days. Six does in the study group received isoxsuprine $(3.3 \mathrm{mg} / \mathrm{kg})$ IM at $8-\mathrm{hr}$ intervals for a total of three doses $(10 \mathrm{mg} / \mathrm{kg})$ and were delivered $24 \mathrm{hr}$ after the first dose at 26 days gestation.

The pregnant doe was killed with $250 \mathrm{mg}$ of IV pentobarbital, and the uterus was exposed. The fetuses were killed with $25 \mathrm{mg}$ of intraperitoneal pentobarbital, delivered with intact fetal membranes to prevent air breathing, and divided into two groups. Lungs were removed from the first group, weighed, and used for lung slice incubation, PC and DSPC measurement, and dry lung weights. Tracheostomy was performed on the second group of fetuses, the chest wall was left intact, and a quasistatic pressure volume study was performed at room temperature as previously described by Kotas and Avery (11). Briefly, the lungs were inflated at maximum pressure of 35 to $40 \mathrm{~cm} \mathrm{H}_{2} \mathrm{O}$. To assume volume equilibrium at maximum pressure, readings were taken for $10 \mathrm{~min}$ after inflation. After each $5 \mathrm{~cm} \mathrm{H}_{2} \mathrm{O}$ deflated pressure changes, volume readings were taken at 1 -min intervals for $3 \mathrm{~min}$. The maximum time between fetal sacrifice and pressure volume studies was $3 \mathrm{hr}$. The fetuses with air leak (17\% of total) were excluded from the study. Deflation stability was defined as lung volume at $10 \mathrm{~cm} \mathrm{H}_{2} \mathrm{O}\left(\mathrm{V}_{10}\right)$ expressed as percentage of maximum lung volume. After pressure volume studies, the lungs were lavaged with 0.5 to $0.75 \mathrm{ml}$ of isotonic saline for five passes, and the lavage fluid of each fetus was collected for analysis of $\mathrm{L} / \mathrm{S}$ ratio.

Fetal lung slice incubation was performed as previously described by Epstein and Farrell (5). A Mcllwain tissue chopper was used to prepare $0.5-\mathrm{mm}$ uniform slices from the entire right lower lobe $(80$ to $250 \mathrm{mg})$. Lower lobes were used because they provide an adequate amount of tissue within a single lobe, thus avoiding interlobe differences in biochemical maturity. Slices of tissue were placed in individual flasks with $4 \mathrm{ml}$ Krebs-Ringer bicarbonate solution (pH 7.4) after equilibration with $95 \% \mathrm{O}_{2}: 5 \% \mathrm{CO}_{2}$. Samples were preincubated in duplicate at $37^{\circ} \mathrm{C}$ under the same gas for 10 min in a Dubnoff metabolic incubator at a shaking rate of 100 cpm. $\left[{ }^{14} \mathrm{C}\right] \mathrm{Choline}(5 \mu \mathrm{Ci} / \mathrm{mmole})$ was added in trace amount with sufficient radioactivity to allow measurement of incorporation into phospholipids. After a 60 -min incubation period under the above conditions, reactions were stopped with ice and the lipids extracted by the method of Folch et al. (7). The lipid phase was separated into specific phospholipids by thin-layer chromatography on Silica Gel $\mathbf{H}$ in the system chloroform:methanol, water, 65:25:4. DSPC was further isolated by the use of osmium tetroxide 
(14) prior to chromatography. Radioactivity in the PC and DSPC spots was determined using a Searle liquid scintillation counter after scraping the phospholipid spot into toluene:PPO:POPOP and expressed as cpm/mg dry lung weight per hr.

Phospholipid concentrations in fetal lung were measured in lower lobe tissue. Lipids were extracted using the Folch method and were then separated on Silica Gel $\mathrm{H}$ in the system chloroform: methanol:water, 65:25:4. The PC spot was visualized by iodination and scraped into vials for determination of phosphorous by the method of Weinhold et al. (20).

DSPC was quantitated on another aliquot by separating the total lipid fraction into DSPC by osmium tetroxide and chromatography. DSPC concentration was determined by measuring the phosphorous as above. Results were expressed as $\mu \mathrm{g}$ of PC and DSPC per mg of dry lung weight.

The $L / S$ ratio on lung lavage fluid was determined by the modified method of Gluck and Kulovich (8), with the omission of acetone precipitation. Fetal lung lavage fluid was extracted with $3 \mathrm{ml}$ of chloroform:methanol, 2:1. The lower phase was aspirated with pipet and evaporated under nitrogen. The residue was resuspended in 15 drops of chloroform and re-evaporated. Chloroform was added and then chromatographed on a Silica Gel H thinlayer chromatogram in the solvent system, chloroform:methanol: water, 65:25:4. The phospholipids were visualized by dipping the chromatogram in bromothymol blue dye. The amounts of lecithin and sphingomyelin were then quantified by spectrodensitometry using a Schoeffel Densitometer.

Statistical analysis of all data was performed using a two-tailed $t$ test.

\section{RESULTS}

Table 1 details the number of animals, fetal body weights, wet lung weight:body weight ratio, and dry lung weight:wet lung weight ratio. There were no significant differences in any of these measurements in the isoxsuprine and saline-treated groups at 26 days gestation.

Figure 1 illustrates the rates of incorporation of $\left[{ }^{14} \mathrm{C}\right]$ choline into total PC and DSPC in lung slices. In the saline-treated groups, the rate of $\left[{ }^{14} \mathrm{C}\right]$ choline incorporation into $\left[{ }^{14} \mathrm{C}\right] \mathrm{PC}$ increased significantly between 26 and 28 days $(2470 \pm 440$ versus $7520 \pm 220$ cpm per mg lung per hr) $(P<0.001)$. There was no difference between 28- and 30-day control fetuses $(7670 \pm 490 \mathrm{cpm}$ per $\mathrm{mg}$ lung per hr). There was also a significant increase in the rate of $\left[{ }^{14} \mathrm{C}\right]$ choline incorporation into $\left[{ }^{14} \mathrm{C}\right] \mathrm{DSPC}$ between 26 and 28 days $(640 \pm 64$ versus $1720 \pm 50 \mathrm{cpm}$ per $\mathrm{mg}$ lung per hr) $(P<$ 0.001 ) and no difference between 28- and 30-day controls (1690 $\pm 70 \mathrm{cpm}$ per $\mathrm{mg}$ lung per $\mathrm{hr}$ ).

In the isoxsuprine-treated group at 26 days gestation, the rate of incorporation of $\left[{ }^{14} \mathrm{C}\right]$ choline into $\left[{ }^{14} \mathrm{C}\right] \mathrm{PC}$ was $4300 \pm 750 \mathrm{cpm}$ per mg lung per $\mathrm{hr}, 75 \%$ higher than the saline-treated group at the same gestation, $(P<0.1)$. There was, moreover, a $50 \%$ increase in $\left[{ }^{14} \mathrm{C}\right]$ choline incorporation into $\left[{ }^{14} \mathrm{C}\right] \mathrm{DSPC}$ in the isoxsuprinetreated group ( $930 \pm 90 \mathrm{cpm}$ per $\mathrm{mg}$ lung per $\mathrm{hr}$ ) when compared to the controls, a significant increase $(P<0.05)$.

Figure 2 illustrates the whole lung PC and DSPC concentrations. In the saline-treated groups, there was a significant increase in the whole lung PC concentration between 26 and 28 days (46.5 \pm 4.2 versus $70.1 \pm 7.1 \mu \mathrm{g} / \mathrm{mg}$ lung $)(P<0.025)$ and no difference between 28 and 30 days ( $86.10 \pm 6.41 \mu \mathrm{g} / \mathrm{mg}$ lung). There was

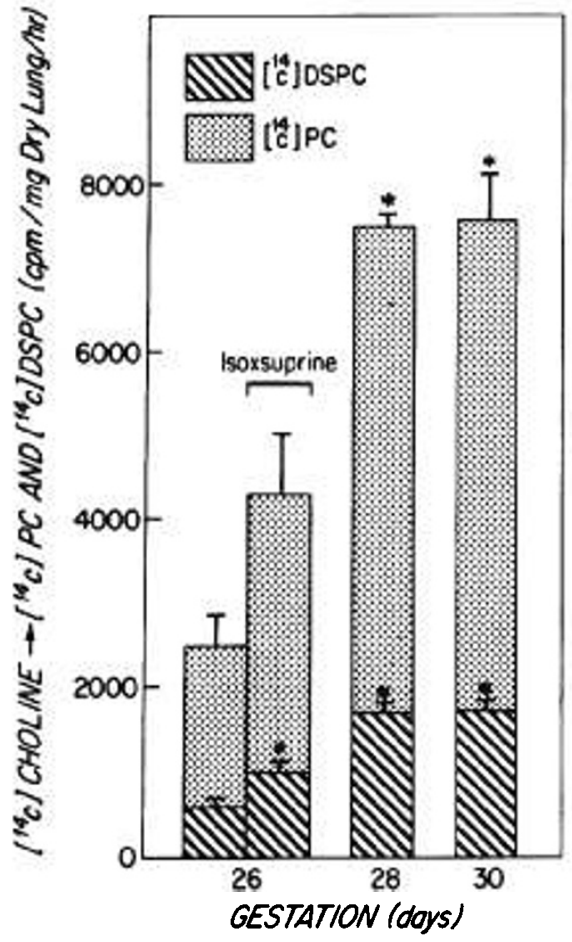

Fig. 1. ${ }^{14}$ Choline incorporation into $\left[{ }^{14} \mathrm{C}\right] \mathrm{PC}$ and $\left[{ }^{14} \mathrm{C}\right] \mathrm{DSPC}$ in fetal lung slices in isoxsuprine and saline-treated litters. Bars, mean incorporation in four to seven litters (16 to 25 fetuses) \pm S. E. *, significantly higher incorporation rate than in 26-day saline-treated litters.

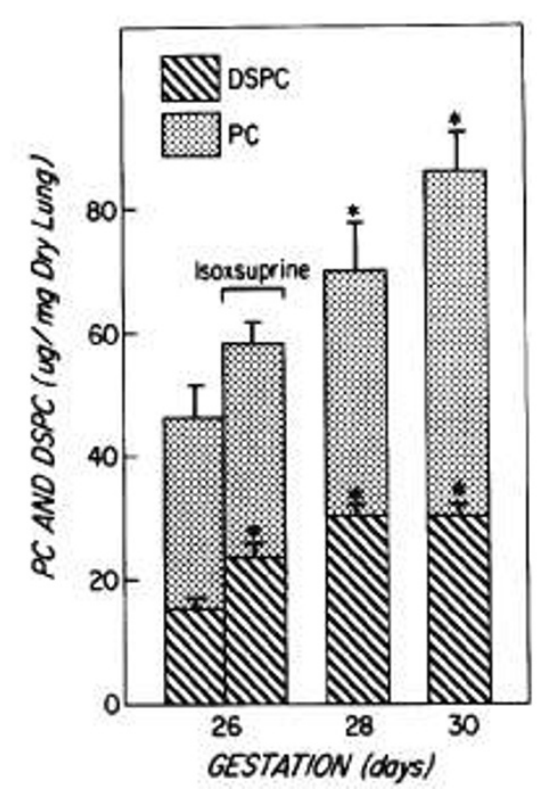

Fig. 2. Fetal lung PC and DSPC concentration in isoxsuprine and saline-treated litters. Bars, mean concentration in four to seven litters (16 to 25 fetuses) \pm S.E. *, significantly higher concentration than in 26-day saline-treated litters.

Table 1. Characteristics of fetal rabbits

\begin{tabular}{|c|c|c|c|c|c|c|}
\hline Gestational age & Treatment & $\begin{array}{c}\text { No. of lit- } \\
\text { ters }\end{array}$ & $\begin{array}{c}\text { No. of fe- } \\
\text { tuses }\end{array}$ & Fetal body wt. & Wet lung wt./body wt. $\times 10^{4}$ & Dry lung wt./wet wt. \\
\hline 26 & Saline & 7 & 41 & $20.2 \pm 3.7^{1}$ & $292 \pm 23$ & $0.13 \pm 0.01$ \\
\hline 26 & Isoxsuprine & 6 & 39 & $24.8 \pm 6.9$ & $295 \pm 31$ & $0.12 \pm 0.01$ \\
\hline 28 & Saline & 4 & 34 & $32.3 \pm 4.3$ & $256 \pm 39$ & $0.11 \pm 0.01$ \\
\hline 30 & Saline & 4 & 29 & $46.2 \pm 14.8$ & $219 \pm 51$ & $0.12 \pm 0.01$ \\
\hline
\end{tabular}

\footnotetext{
${ }^{1}$ Mean \pm S.D.
} 
also a significant increase in whole lung DSPC concentration between 26 and 28 days $(15.9 \pm 1.0$ versus $29.4 \pm 0.8 \mu \mathrm{g} / \mathrm{mg}$ lung) $(P<0.001)$ and no difference between 28 and 30 days $(28.7 \pm 2.0$ $\mu \mathrm{g} / \mathrm{mg}$ lung).

The isoxsuprine-treated group showed a significant increase in total lung DSPC concentration $(23.4 \pm 2.2 \mu \mathrm{g} / \mathrm{mg}$ lung $)(P<0.01)$ and a tendency toward an increase in total lung $P C$ concentration as well $(58.4 \pm 3.7 \mu \mathrm{g} / \mathrm{mg}$ lung) $(P<0.1)$ when compared to the saline-treated group. There was no significant change in the percentage of saturation of PC (i.e., DSPC:PC) between isoxsuprine $(40 \pm 1.4 \%)$ and saline-treated groups $(35 \pm 2 \%)$.

Figure 3 illustrates the $\mathrm{L} / \mathrm{S}$ ratio in lung lavage fluid. In the saline-treated groups, there were significant increases in $\mathrm{L} / \mathrm{S}$ ratio from 26 to 28 days $(1.4 \pm 0.2$ to $2.9 \pm 0.2)(P<0.005)$ and from 28 to 30 days $(5.6 \pm 0.3)(P<0.001)$. The isoxsuprine-treated group at 26 days showed a significantly higher $\mathrm{L} / \mathrm{S}$ ratio, $2.4 \pm$ 0.2 , when compared to the controls $(P<0.025)$.

Figure 4 illustrates the deflation pressure volume curves in the saline-treated groups. There were significant changes of pressure volume characteristics in these controls between 26,28 , and 30 days. Pressure volume curves in the isoxsuprine and saline-treated groups at $\mathbf{2 6}$ days are compared in Figure 5. Isoxsuprine treatment

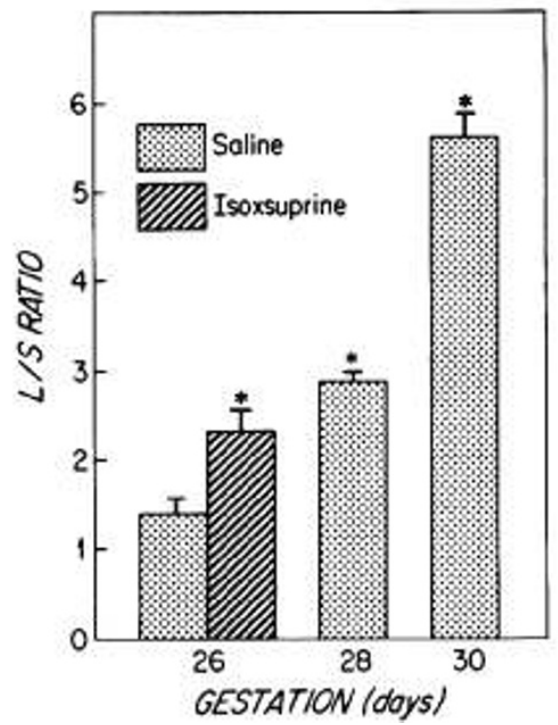

Fig. 3. L/S ratio in fetal lung lavage in isoxsuprine and saline-treated litters. Bars, mean L/S ratio in four to seven litters (13 to 21 fetuses) \pm S.E. *, significantly higher $\mathrm{L} / \mathrm{S}$ ratio than in 26 -day saline-treated litters.

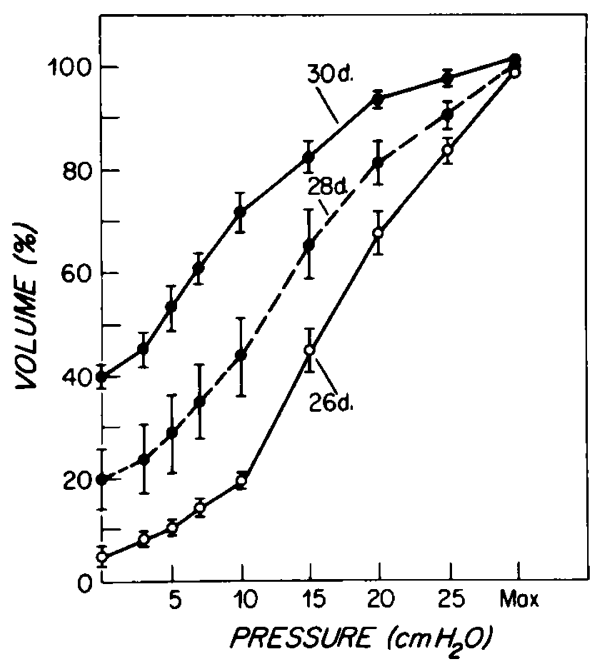

Fig. 4. Deflation pressure-volume characteristics in saline-treated litters at 26,28 , and 30 days gestation. Points, mean \pm S.E. from four to seven litters (13 to 21 fetuses).

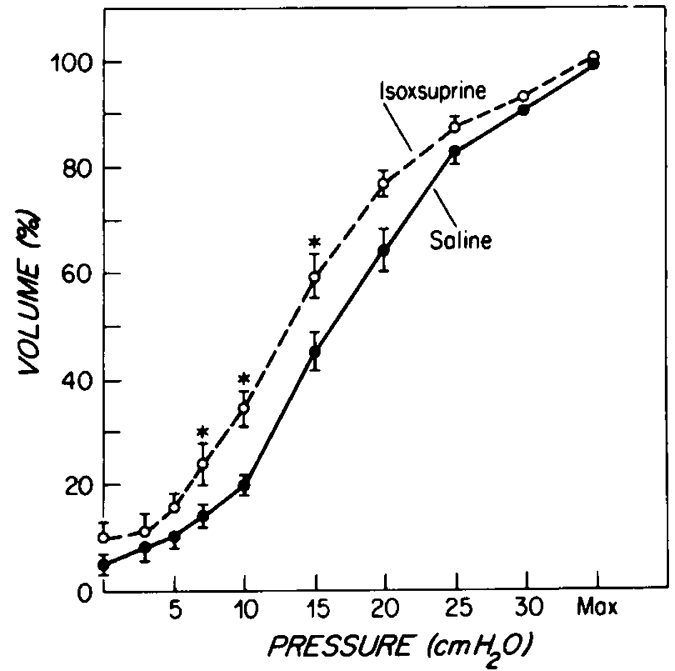

Fig. 5. Deflation pressure-volume characteristics in isoxsuprine and saline-treated litters at 26 days. Points, mean \pm S.E. for six to seven litters (16 to 21 fetuses).

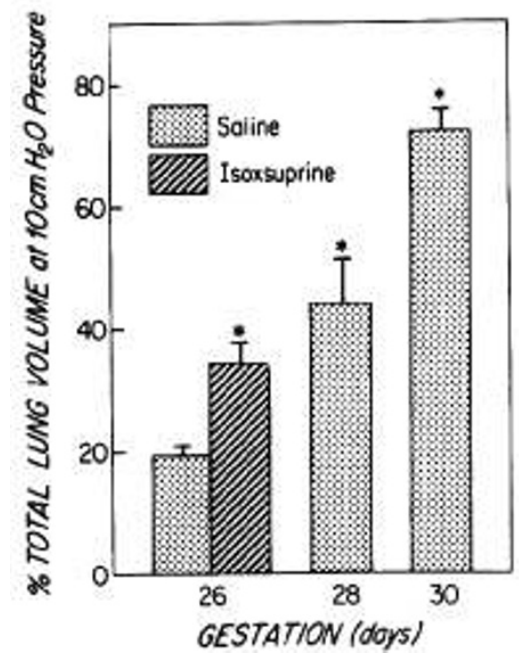

Fig. 6. Deflation stability expressed as percentage of total lung volume at $10 \mathrm{~cm} \mathrm{H}_{2} \mathrm{O}$ pressure $\left(\mathrm{V}_{10}\right)$ in isoxsuprine and saline-treated litters. Bars, mean \pm S.E. $V_{10}$ in four to seven litters (13 to 21 fetuses). *, significantly higher $V_{10}$ than in the 26-day saline-treated litters.

led to significant increases of mean deflated lung volumes at 15 (59.1 \pm 4.4 versus $44.6 \pm 3.8)(P<0.05), 10$ (34.3 \pm 3.7 versus 19.4 $\pm 0.8)(P<0.01)$, and $7(23.9 \pm 4.3$ versus $14.0 \pm 1.2)(P<0.05)$ $\mathrm{cm} \mathrm{H}_{2} \mathrm{O}$ when compared to the saline-treated group. However, there were no significant changes of deflated lung volume below $7 \mathrm{~cm} \mathrm{H}_{2} \mathrm{O}$.

Figure 6 illustrates the mean values of deflation stability expressed as $\mathrm{V}_{10}$, the $\%$ maximum lung volume at $10 \mathrm{~cm} \mathrm{H}_{2} \mathrm{O}$. There were significant increases in deflation stability in the saline-treated groups. Mean $\mathrm{V}_{10}$ increased from $19.4 \pm 0.8 \%$ at 26 days to 43.5 $\pm 7.6 \%$ at 28 days $(P<0.005)$ and to $71.9 \pm 3.7 \%(P<0.05)$ at 30 days. The isoxsuprine-treated fetuses at 26 days had a significantly higher deflation stability compared to the controls.

\section{DISCUSSION}

The administration of isoxsuprine to the pregnant rabbit for 24 $\mathrm{hr}$ at 25 to 26 days gestation resulted in a significant increase in (1) the rate of incorporation of choline into DSPC in fetal lung slices; (2) concentration of DSPC in fetal lung tissue; (3) the L/S ratio of fetal lung lavage fluid; and (4) the fetal lung's deflation stability.

We selected this gestational age because results in saline-injected rabbits showed that after 26 days gestation, the fetal lung demonstrated a marked increase in all aspects of fetal lung phospho- 
lipid metabolism measured. This gestational timetable agrees with previous observations of gestational changes in fetal rabbit lung phospholipid metabolism by other investigators $(11,15)$.

Our interest in the effect of beta-adrenergic drugs in the fetal lung was initiated by the previous clinical observations of the effect of beta-adrenergic drugs on the incidence of RDS after fetal exposure to these drugs in mothers with premature labor. Kero et al. (10) reported that all 11 premature infants were free of RDS after exposure to isoxsuprine prior to delivery. Boog et al. (2) demonstrated a significant decrease in the incidence of RDS in infants less than $2300 \mathrm{~g}$ when mothers had received ritodrine, another beta-adrenergic drug, when compared to a control group. However, in separate studies, Taeusch (17) and Liggins (13) were unable to demonstrate a decreased incidence of RDS after the use of beta-adrenergic drugs for premature labor.

Most previous studies of the effect of beta adrenergic drugs on fetal-pulmonary surfactant have concentrated on the release of surfactant. Wyszogrodski et al. (21) observed a significant improvement in deflation pressure volume characteristics in rabbit newborns after isoxsuprine injection of the fetuses three hr prior to delivery. Bergman et al. (1) reported a similar improvement in pressure-volume characteristics of fetal rabbit lungs at 28 days gestation three hr after terbutaline administration to the fetus. In addition, Enhorning et al. (4) found a decreased surface tension and an increased $\mathrm{L} / \mathrm{S}$ ratio in the pulmonary fluid of the rabbit fetuses at 27 days gestation, $4 \mathrm{hr}$ after isoxsuprine administration. These observations were supported by Lawson et al. (12) who administered epinephrine directly to chronically catheterized fetal sheep. They noted a marked increase in the efflux of surfactant in fetal lung liquid measured both physiologically as a decrease in surface tension on a modified Wilhelmy balance and biochemically as an increase in the amount of DSPC. Finally, Corbet $e t$ al. (3) observed an increase in lung stability in fetal rabbits after injection with isoxsuprine, an effect that could be blocked by treatment with propranolol. They hypothesized that beta adrenergic receptors were probably the final mediators of surfactant release before air breathing. The higher $\mathrm{L} / \mathrm{S}$ ratio in tracheal lavage and the increased deflation stability after isoxsuprine treatment in the current study supports these observations.

Our finding that the total lung PC and DSPC in the rabbit fetuses increased at 26 days gestation after $24 \mathrm{hr}$ of maternal isoxsuprine administration is consistent with the findings of Hayden et al. (9). We found a significant increase of total lung DSPC and a tendency toward an increased total lung PC as well in isoxsuprine-treated rabbit fetuses. We expressed the amount of phospholipids as total PC and DSPC per mg dry lung to avoid potential errors from changes in lung weight due to a decrease in lung water content in isoxsuprine-treated fetuses as previously reported by Enhorning et al. (4). We were unable to confirm this observation of "lung drying," finding no difference in lung water content or lung weight:body weight ratio after isoxsuprine treatment. This difference between the present study and that of Enhorning et al. may be due to the different gestational ages of the rabbit fetuses ( 26 versus 28 days, respectively) and the consequent differences in alveolar-capillary development between the two groups or to the different experimental design (repeated maternal injection and $24 \mathrm{hr}$ exposure versus surgery and direct fetal injection with single exposure of $4 \mathrm{hr}$ ).

Finally, our observation of a significant increase in the rate of choline incorporation into DSPC favors the hypothesis that the beta adrenergic drug also led to an increase in DSPC synthesis. This observation is contrary to the conclusion of Hayden et al. (9) who concluded that isoxsuprine led to a decrease in total lung PC synthesis. They did not measure DSPC separately. Hayden et al. based their conclusion on the observation of a decreased activity of choline phosphotransferase, the enzyme catalyzing the final step of the choline incorporation pathway. Specific enzyme assays in lipid systems are fraught with problems due to the difficulty of exogenous substrate in gaining access to specific intracellular compartments (19). These difficulties have resulted in disagreement among investigators in this area concerning the activities of enzymes of the choline incorporation pathway. In addition, the meaning of a single enzyme activity for the overall rate of synthesis of $\mathrm{PC}$ is uncertain when the identity of the rate-limiting enzyme is unknown. These problems make it difficult to relate Hayden's observation of a decreased activity of choline phosphotransferase activity to overall PC synthesis. Our findings of increases in both the overall rate of the major de novo pathway for the synthesis of lung DSPC and in total lung DSPC concentration indicate that despite its action to increase the secretion of surfactant into the alveoli, isoxsuprine has a favorable net effect of DSPC accumulation in fetal lung.

In summary, we have shown an increase in the rate of incorporation of choline into DSPC, increased total lung DSPC, elevated $\mathrm{L} / \mathrm{S}$ ratio in lung lavage fluid, and finally a significant increase in lung deflation stability in rabbit fetuses at 26 days gestation after administration of isoxsuprine to the pregnant rabbit does for $24 \mathrm{hr}$. Therefore, the net effect of isoxsuprine appears to enhance fetal pulmonary maturation in rabbit pregnancy.

\section{REFERENCES AND NOTES}

1. Bergman, B., Hedner, T., and Lundborg, P.: Effects of terbutaline on the pressure volume relationship in fetal rabbit lung. Acta Obstet. Gynecol. Scand., 57: 323 (1978).

2. Boog, G., Brahem, M. B., and Gaudar, R.: Beta-mimetic drugs and possible prevention of respiratory distress syndrome. Br. J. Obstet. Gynaecol., 82: 285 (1975).

3. Corbet, A. J., Flax, P. K., and Rudolph, A. J.: Effect of sympathetic stimulation on pulmonary surfactant. Pediatr. Res., 4: 569 (1977).

4. Enhorning, G., Chamberlain, D., Contreras, C., Burgoyne, R., and Robertson, B.: Isoxsuprine-induced release of pulmonary surfactant in the rabbit fetus. Am. J. Obstet. Gynecol., 129: 197 (1977).

5. Epstein, M. F., and Farrell, P. M.: The choline incorporation pathway: primary mechanism for de novo synthesis in fetal primate lung. Pediatr. Res., 9: 658 (1975).

6. Farrell, P. M., and Avery, M. E.: Hyaline membrane disease. Am. Rev. Respir. Dis., 111: 657 (1975).

7. Folch, I., Lees, M., and Stanley, G. H. S.: A simple method for the isolation and purification of total lipids from animal tissues. J. Biol. Chem., 226: 497 (1957).

8. Gluck, L., and Kulovich, M. V.: Lecithin/sphingomyelin ratios in amniotic fluid in normal and abnormal pregnancy. Am. J. Obstet. Gynecol., 115: 539 (1973).

9. Hayden, W., Olson, E. B., Jr., and Zachman, R. D.: Effect of maternal isoxsuprine on fetal rabbit lung biochemical maturation. Am. J. Obstet. Gynecol., 129: 691 (1977).

10. Kero, P., Hervonen, T., and Valimaki, I.: Prenatal and postnatal isoxsuprine and respiratory distress syndrome. Lancet, 2: 198 (1973).

11. Kotas, R. V., and Avery, M. E.: Accelerated appearance of pulmonary surfactant in the fetal rabbit. J. Appl. Physiol., 30: 358 (1971).

12. Lawson, E. E., Brown, E. R., Torday, J. S., Madansky, D. L., and Taeusch, H. W.: Influence of epinephrine on fetal pulmonary fluid production and surfactant release. Am. Rev. Respir. Dis., 118: 1023 (1978).

13. Liggins, G. C.: Prenatal glucocorticoid treatment: prevention of RDS. In: 70th Ross Conference Report: Lung maturation and the prevention of hyaline membrane disease. p. 97-103 (Ross Laboratories, Columbus, Ohio, 1975).

14. Mason, R. J., Nellenbogen, J., and Clements, J. A.: Isolation of DSPC with osmium tetroxide. J. Lipid Res., 17: 281 (1976).

15. Rooney, S. A., Gobran, L. I., Marino, P. A., Maniscalco, W. M., and Gross, I.: Effects of betamethasone on phospholipid content, composition and biosynthesis in the fetal rabbit lung. Biochim. Biophys. Acta, 572: 64 (1979).

16. Smith, B. T.: Cell line A549: A model system for the study of alveolar type II cell function. Am. Rev. Respir. Dis., 115: 285 (1977).

17. Taeusch, H. W.: Tribulations of clinical trials. In: 70th Ross Conference Report: Lung maturation and the prevention of hyaline membrane disease. p. 90-96 (Ross Laboratories, Columbus, Ohio, 1975).

18. Tepperman, H. M., Beydoun, S. N., and Abdul-Karim, R. W.: Drugs affecting myometrial contractility in pregnancy. Clin. Obstet. Gynecol., 20: 423 (1977).

19. Van Golde, L. M. G.: Metabolism of phospholipids in the lung. Am. Rev. Respir. Dis., 114: 977 (1976).

20. Weinhold, P. A., and Villee, C. A.: Phospholipid metabolism in the liver and lungs of rats during development. Biochim. Biophys. Acta, 106: 540 (1965).

21. Wyszogrodski, J., Taeusch, H. W., Jr., and Avery, M. E.: Isoxsuprine induced alterations of pulmonary pressure-volume relationships in premature rabbits. Am. J. Obstet. Gynecol., 119: 1107 (1974).

22. Requests for reprints should be addressed to: Vallop Kanjanapone, M.D., Fellow in Neonatology, Joint Program in Neonatology, 221 Longwood Ave., Boston, MA 02115 (USA).

23. This research was supported by a grant from the Charles H. Hood Foundation.

24. Received for publication April 9, 1979.

25. Accepted for publication July 12, 1979. 